\title{
Docência em Educação Física Inclusiva: esgotamentos vividos no contexto do ensino remoto brasileiro
}

\author{
Teaching in Inclusive Physical Education: exhaustions lived in the context of brazilian remote teaching \\ Docencia en Educación Física Inclusiva: agotamientos vividos en el contexto de la educación remota brasileña
}

\author{
Roseli Belmonte Machado \\ Universidade Federal do Rio Grande do Sul - UFRGS, Brasil \\ robelmont@yahoo.com.br \\ (iD) \\ https://orcid.org/0000-0001-5653-1175
}

\author{
Denise Grosso da Fonseca \\ Universidade Federal do Rio Grande do Sul - UFRGS, Brasil \\ dgf.ez@terra.com.br \\ (iD https://orcid.org/0000-0001-6206-4729
}

\begin{abstract}
Resumo:
O ano de 2020 ficou marcado pela pandemia do Covid-19, fato que impactou os diferentes modos de vida. O distanciamento social foi um dos modos de conter a pandemia, ocasionando a cessão das aulas presenciais no Brasil, migrando para o modelo de ensino remoto. Nessa realidade, este estudo, que considera o ensino remoto dentro do contexto social, político e econômico brasileiro, teve como objetivo problematizar a docência de professores de Educação Física escolar no contexto das aulas remotas no Brasil, focando no trabalho com alunos considerados de inclusão. Um estudo exploratório qualitativo, que realizou entrevistas com professores de Educação Física. Foram 116 entrevistas, realizadas através de questionário elaborado na plataforma Google. A análise seguiu o aporte das pesquisas pós-estruturalistas de pensar a Educação, apoiada nos conceitos de governamentalidade e de docência. A partir da análise são trazidos dois pontos para discussão: as práticas trabalhadas na Educação Física com alunos de inclusão no ensino remoto e a ideia de crise na docência em uma Educação Física inclusiva. Com isso, argumenta-se que a falta do contato com os alunos na escola e as desigualdades do contexto social e econômico brasileiros podem ocasionar práticas de exclusão e contribuir para um esgotamento docente.
\end{abstract}

PalaVras-CHaVE: Ensino Remoto, Educação Física, Inclusão, Governamentalidade, Docência.

\section{Abstract:}

The year 2020 was marked by the pandemic of Covid-19, a fact that impacted on different aspects of life. The social distancing was one of the ways to contain the pandemic, causing the cessation of face-to-face classes in Brazil, migrating to a remote teaching model. In this reality, this study, which considers remote teaching within the Brazilian social, political, and economic context, aimed to problematize the teaching of Physical Education in the context of remote classes in Brazil, focusing on the work with those considered students of inclusion. It is a qualitative exploratory study, in which interviews with Physical Education teachers were conducted. 116 interviews were carried out through a questionnaire elaborated on the Google platform. The analysis followed the contribution of post-structuralist researches to think about Education, supported by the concepts of governamentality and teaching. From the analysis, two points are brought up for discussion: the practices worked in Physical Education with students of inclusion in remote education, and the idea of teaching crisis in inclusive Physical Education. Thus, it is argued that the lack of contact with students at school and the inequalities in the Brazilian social and economic context can lead to exclusionary practices and contribute to teaching burnout.

KEYWORDS: Remote Teaching, Physical Education, Inclusion, Governamentality, Teaching. 


\section{Resumen:}

El año 2020 estuvo marcado por la pandemia Covid-19, hecho que impactó diferentes formas de vida. El distanciamiento social fue una de las formas de contener la pandemia, provocando el cese de las clases presenciales en Brasil, migrando al modelo de enseñanza remota. En esta realidad, este estudio, que considera la enseñanza remota en el contexto social, político y económico brasileño, tuvo como objetivo problematizar la enseñanza remota de los docentes de Educación Física en Brasil, centrándose en el trabajo con estudiantes considerados de inclusión. Se realizó un estudio exploratorio cualitativo, que entrevistó a profesores de Educación Física. Fueron 116 entrevistas, realizadas mediante el envío de un cuestionario elaborado en la plataforma de Google. El análisis siguió la contribución de la investigación postestructuralista en Educación, apoyada en los conceptos de gubernamentalidad y enseñanza. A partir del análisis, se plantean dos puntos para la discusión: las prácticas trabajadas en Educación Física con estudiantes de inclusión en educación remota y la idea de crisis en la enseñanza en una Educación Física inclusiva. Así, se argumenta que la falta de contacto con los estudiantes en la escuela y las desigualdades del contexto social y económico brasileño pueden conducir a prácticas excluyentes y contribuir al agotamiento docente.

Palabras ClaVE: Enseñanza remota, Educación Física, Inclusión, Gubernamentalidad, Docencia.

\section{INTRODUÇÃO: OLHARES PARA O CENÁRIO BRASILEIRO}

É fundamental destacar alguns pontos que compõem o cenário destes tempos para situar o pensamento e o contexto deste estudo. Como sabemos e vivemos, o ano de 2020 trouxe a maior crise sanitária mundial deste início de século - a pandemia do Covid-19, em decorrência do vírus Sars-Cov-2 fato que impactou os diferentes modos de vida. Em específico, no Brasil, essa situação é agravada pelas condições sociais, pelas condições econômicas e pelas condições políticas. Estamos diante de um cenário que, dentre outros fatores, desconsidera saberes de ordem científica em prol de discursos com interesses econômicos, que manifesta um descrédito nas instituições, que busca esconder casos ilícitos da condução da vida política e que incita ao ódio, à violência e a exclusões de alguns grupos identitários. Fatores esses que contribuem e são parte de um discurso que procura abalar as bases democráticas do país. Nós brasileiros, que estávamos na égide de um governo neoliberal, agora, para além, também nos aproximamos de modos de governo que flertam com um tipo de fascismo, no sentido de excluir, expulsar, exterminar o outro.

Estávamos vivendo, nos últimos anos no Brasil, o que compreendemos - a partir de um aporte teórico dos estudos do filósofo francês Michel Foucault - como uma governamentalidade neoliberal que, dentre diferentes pilares, aciona que todos deveriam estar inseridos no jogo econômico, embora em níveis distintos. Seria a regra de uma "não-exclusão do jogo econômico, que, fora disso, deve se desenrolar por si mesmo" (Foucault, 2008, p. 278). Além dessa característica, compreende-se que uma governamentalidade neoliberal busca educar a população no sentido de que se viva em condiçóes de sustentabilidade, de empresariamento e de autocontrole, mas em diferentes níveis de participação (Lopes, 2009). Uma racionalidade social, política e econômica que procura "estender a racionalidade do mercado, os esquemas de análise que ela propõe e os critérios de decisão que sugere a domínios não exclusivamente ou não prioritariamente econômicos" (Foucault, 1997, p. 96), tornando-se uma forma de vida, maximizando a competição, o empresariamento, produzindo o capital humano e as ideias de liberdade, colocando o Estado a seu serviço.

Podemos entender que, para atingir tal propósito, as reivindicações de direitos de grupos marginalizados e os movimentos sociais que trabalham em prol da inclusão eram capturados e usados como instrumentos do neoliberalismo. Assim, a busca pela inclusão também poderia ser vista como uma estratégia que visava posicionar e conduzir os sujeitos dentro de uma racionalidade neoliberal, colaborando para um gerenciamento dos riscos numa vertente de ação biopolítica, ou seja, que toma o corpo populacional como investimento para controle de riscos, capturando - e então controlando e gerenciando - cada um e todos, incluindo nas redes do mercado de um jogo econômico. Ao estar nessas redes, faz-se necessário que se permaneça nesse lugar e, para isso, cada um deve buscar tornar-se produto. É preciso que cada um invista em seu capital humano e se torne um empresário de si, responsável pelos cuidados consigo. Há uma responsabilização do sujeito e um desinvestimento da responsabilidade do Estado que, ao colocar os sujeitos 
nas redes, o responsabiliza pela sua permanência. Um movimento que captura, inclui, mas delega ao sujeito a sua permanência, se constituindo num tipo de inclusão, muitas vezes com características excludentes, considerando a ausência de garantias que possibilitem sua continuidade no processo configurando-se num tipo de precarização da existência humana (Lockmann, 2020).

Como um movimento consubstanciado e também tomado pelo neoliberalismo, a inclusão poderia ser vista como uma ação que deveria atingir a todos, indistintamente, e que se configurava como um imperativo de Estado (Lopes e Fabris, 2013). A partir de tal perspectiva, em que pesem os avanços que temos tido em relação aos processos de inclusão, é preciso compreender que falávamos de uma estratégia social e política que também governava os diferentes sujeitos, dentro de um modo de vida neoliberal, mas que dava visibilidade e voz a distintos grupos identitários.

O professor Silvio Gallo, a partir de uma análise voltada para o contexto brasileiro, traz que estávamos vivendo a égide de uma governamentalidade democrática, desde o processo de redemocratização do país, tendo como marco a Constituição Federal de 1988 e que tinha na cidadania o princípio fundamental (Gallo, 2013):

Um tipo de governamentalidade democrática que pressupunha uma sociedade civil organizada face ao Estado; uma economia que regulava as trocas e garantia a potência do mercado, com geração de riquezas; uma população, que é alvo das ações preventivas do Estado na garantia de sua qualidade de vida e tendo a liberdade e a não submissão dos cidadãos como valor fundamental dessa organização social e política. [...] (Gallo, 2013, p.204).

Mas, ao mesmo tempo, uma racionalidade que exercia um controle sobre os indivíduos de modo que eles se acreditassem cidadãos livres, participativos e peças centrais no jogo democrático. Um processo no qual o sujeito se sentia um cidadão incluído. Em que pesem as problematizações acerca do jogo entre direitos e governo dos sujeitos, é preciso destacar que estávamos vivendo um processo de produção de direitos, nos mais distintos âmbitos. Tal produção, que pode ser compreendida como um modo insidioso de governamento, de uma estratégia biopolítica e neoliberal, também trouxe uma proliferação de saberes que hoje são considerados como necessários de serem garantidos: a necessidade de que todos estejam na escola, a acessibilidade, a inclusão social, a inserção no mundo do trabalho, dentre outros.

Todavia, a partir das recentes configurações políticas, tais questões têm se esvaziado. Notamos uma inclinação pela busca da exclusão, da desvalorização de alguns grupos, do exercício de práticas racistas, da retirada de diferentes direitos, permeados por uma incitação ao ódio, à violência e a exclusões nas diferentes esferas sociais. É possível dizer que caminhamos para uma forma de fascismo no Brasil. Para Lazzarato (2019) "a eleição de Bolsonaro para presidente do Brasil marca uma radicalização da onda neofascista, racista e sexista que assola o planeta" (p. 20). Tal eleição seria o efeito de uma política de financeirização do crédito, que tinha propósitos de inclusão dos sujeitos no jogo econômico, mas que transformou o usuário social em cliente endividado. Para o autor, a micropolítica do crédito criou as condições para uma micropolítica fascista. A partir de um cultivo do neoliberalismo, atravessando diferentes governos, chegamos a uma política que pretendia melhorar as condições de vida e reduzir a pobreza pelos mecanismos de finança. Algo que acarretou numa crise política e econômica, gerando uma lógica de confronto, reintensificando "guerra de classe, de raça e de sexo, que é, desde sempre, o fundamento do capitalismo" (Lazzarato, 2019, p. 37).

Lockmann, em artigo intitulado Governamentalidade neoliberal fascista e o direito à escolarização nos oferece uma reflexão sobre isso. Ao considerar a pandemia da Covid-19, a autora afirma:

A pandemia do Coronavírus (Covid-19) coloca em xeque a "eficácia" do neoliberalismo na gestão da vida da população; evidencia que o empresariamento da sociedade nada mais é do que a precarização da existência humana; e expõe o viés fascista de um Estado cuja primazia da economia faz, da (des)valorização de algumas vidas, uma forma de governar na crise, a partir da materialização de práticas de exclusão daqueles sujeitos e grupos que não respondem a um modelo instituído de vida e de ordem (Lockmann, 2020, p 1.) 
Para a autora temos deslocamentos que mostram estarmos vivendo uma governamentalidade neoliberal fascista, compreendida como uma governamentalidade que "mantém alguns princípios neoliberais, mas articula a eles a face grotesca e ubuesca de um fascismo, ao mesmo tempo estatal e cotidiano, ao mesmo tempo molar e molecular" (Lockmann, 2020, p. 3). Como dito ao início, para além de estarmos vivermos na égide de uma governamentalidade neoliberal no Brasil, nos aproximamos de formas fascistas de governo, que, dentre outras situações, trazem práticas de exclusão.

Dentro dessa moldura está a tela educacional vivida no Brasil no ano de 2020. Como sabemos, um dos modos de contenção da propagação do vírus Sars-Cov-2, amplamente divulgado pelos órgãos de saúde, foi a adoção do distanciamento social. No território brasileiro, grande parte dos estados e municípios, mesmo em contraponto ao Governo federal, adotou essa prática, ocasionando a cessão das aulas presenciais nas instituições de ensino, a partir de março de 2020, migrando para o modelo que ficou conhecido como ensino remoto.

A partir da realidade supracitada, este estudo, que considera o ensino remoto dentro do contexto social, político e econômico brasileiro, se coloca a problematizar a docência de professores de Educação Física escolar no contexto das aulas remotas no Brasil, focando no trabalho com os alunos considerados de inclusão, alunos com deficiência.

\section{Metodologia: CAMinhos, conceitos E companhias de PESQUiSA}

O objetivo desta pesquisa é o de problematizar a docência de professores de Educação Física escolar no contexto das aulas remotas no Brasil, focando no trabalho com os alunos considerados de inclusão. Para tal propósito realizou-se um estudo de cunho exploratório junto a professores de Educação Física que estivessem atuando nas escolas brasileiras no momento do distanciamento social. Foram professores de instituições públicas e privadas, de diferentes esferas, atuantes em turmas regulares de ensino de alunos com e sem deficiência. O contato foi sistematizado pelo uso de questionário com questões abertas e fechadas, elaborado na plataforma Google - Google Forms. Foram temas das questões: a compreensão do contexto do ensino remoto; o trabalho realizado no ensino remoto com foco nas metodologias e conteúdos; a atenção aos alunos considerados de inclusão. A escolha dos sujeitos seguiu dois critérios: 1) ser professor que atua na Educação Básica em escolas brasileiras das diferentes redes - municipais, estaduais, federais e privadas; 2) estar trabalhando com Educação Física escolar no momento de distanciamento social. Foram convidados professores que participaram de diferentes edições de curso de extensão para formação docente na universidade ${ }^{1}$. Na sequência, a pesquisa também foi divulgada em redes sociais, destacando os critérios dos sujeitos que poderiam participar, acompanhados de termo de adesão com os devidos cuidados éticos. Todos os questionários estão de posse dos pesquisadores e comprovam atenção aos critérios da pesquisa. A pesquisa ora apresentada foi realizada em duas fases: a primeira em maio de 2020 e a segunda em agosto de 2020. A primeira fase contou com a contribuição de 43 professores e na segunda etapa conta com 73 professores de diferentes regióes do Brasil, totalizando 116 colaborações de docentes que atuam com o Ensino Fundamental, com o Ensino Médio e com a Educação Infantil. Importa destacar que este estudo faz parte de pesquisa registrada no comitê de ética em pesquisa da universidade ${ }^{2}$.

A análise está baseada na perspectiva dos estudos educacionais pós-estruturalistas. Compreende-se que as relações entre saber e poder são acionadas em distintos modos de subjetivação, que o poder é relacional, que os mecanismos de regulação e controle estão dispersos no tecido social e que a escola é um desses mecanismos, sendo central na tarefa de normalização, disciplinarização, regulação e governo das pessoas e das populações (Silva, 1994). Destaca-se que pesquisar nessa perspectiva pode contribuir na compreensão dos processos de produção e de constituição da Educação Física escolar e da docência nestes tempos, analisando o modo como esses processos estão se desenvolvendo e quais são os seus efeitos na constituição dos sujeitos. 
Os principais conceitos teórico-metodológicos do estudo são o de governamentalidade, na perspectiva de Foucault (2008), como as lentes teóricas que ajudam a compreender o contexto atual a partir das artes de governar; e o conceito de docência, numa perspectiva que compreende a docência como presença, no sentido de Larrosa (2018).

Sobre governamentalidade, Foucault, ao ministrar um curso no Collège de France, em 1978, conhecido no Brasil como Segurança, Território e População, chama de governamentalidade:

[...]o conjunto constituído pelas instituições, os procedimentos, análises e reflexões, os cálculos e as táticas que permitem exercer essa forma bem específica, embora muito complexa, de poder que tem por alvo principal a população, por principal forma de saber a economia política e por instrumento técnico essencial os dispositivos de segurança. Em segundo lugar, por "governamentalidade", entendo a tendência, a linha de força que, em todo o Ocidente, não parou de conduzir, e desde há muito, para a preeminência desse tipo de poder que podemos chamar de "governo" sobre todos os outros - soberania, disciplina - e que trouxe, por um lado, o desenvolvimento de toda uma série de aparelhos específicos de governo [e, por outro lado], o desenvolvimento de toda uma série de saberes. Enfim, por governamentalidade, creio que se deveria entender o processo, ou antes, o resultado do processo pelo qual o estado de justiça da Idade Média, que nos séculos XV e XVI se tornou o Estado administrativo, viu-se, pouco a pouco, "governamentalizado" (Foucault, 2008, p.143-144).

A partir disso, no desenrolar de sua obra, a maneira como Foucault compreende a governamentalidade ultrapassa esse entendimento, essas três explicações. Além do curso supracitado, no curso Nascimento da Biopolítica, ministrado em 1979, também no Collége de France, Foucault (2008b) apresenta uma análise sobre os modos de exercício de governo a partir da égide da governamentalidade: "o que propus chamar de governamentalidade não é mais que uma proposta de grade de análise para essas relações de poder" (Foucault, 2008 b, p. 258). Nesse curso, Foucault nos conduz a uma problematização das racionalidades políticas presentes no liberalismo e em suas formas de neoliberalismo. Entretanto, a partir do curso proferido no ano de 1980, intitulado $O$ Governo dos Vivos, Foucault (2011) enriquece a discussão iniciada, agregando à noção de governo que vinha desenvolvendo uma noção de um governo ético desenvolvido sobre si mesmo numa relação com a verdade. É dentro dessa perspectiva que o conceito de governamentalidade entra neste trabalho, sendo compreendida como um modo de analisar as artes de governar e as relações de poder nelas implícitas.

Para abordar o conceito de docência, embora seja discutido por diferentes vieses, escolhemos para esta investigação uma abordagem a partir das considerações do professor Jorge Larrosa (2018). Para o autor o ofício de professor é algo que tem a ver com a artesania, com a realização de uma obra, com uma condição e com uma realização justa e adequada dessa condição. Algo inseparável do que se faz e do que se é, que tem relação com uma potência de atuar, com entregar-se e submeter-se e com cumprir os deveres que se traz consigo.

[...] ofício de professor não tem nada a ver com competências, com técnicas didáticas ou com resultados, mas com ser "de verdade" (seja isso o que seja); o que incorpora uma série de hábitos que constroem um éthos, um costume, um modo de ser e de atuar, um modo de viver; nisso que o ofício deve ser exercido com devoção, entregando-se a ele, respeitando-o, sem qualquer sentimento de opressão sobre nossa natureza em função do nosso dever; isso que implica compromisso e, às vezes, lutas; nisso de que o ofício de professor implica questionar tudo; e, sobretudo, fugindo de toda solenidade e de toda gradilequência; reconheço-me também no que o ofício tem de íntimo e de cotidiano, de algo que se faz a cada dia (e não em momentos especiais) e de um modo sempre menor, com gestos mínimos, modestos, quase desapercebidos, sem espetáculos, nem artifícios (Larrosa e Rechia, 2018b, p. 319-320).

Além de pensar o ofício do professor como algo de um éthos, de um modo de viver, Larrosa e Rechia (2018) também nos oferecem uma reflexão da docência como presença. O professor como aquele que, com sua presença - no sentido de estar presente naquilo que faz - torna presente a matéria de estudo e convoca a presença do aluno. A partir de uma exposição de Fernando Gonzalez que diz "Em mis clases la assistência no es obligatoria, pero la presencia si”, desenvolvem que a presença é tripla: do professor; da matéria de estudo que o professor a faz presente, é a sua arte - e, dos estudantes, que estando, devem estar ali (Larrosa e Rechia, 2018). 
Cabe fazer uma ressalva à ideia de matéria de estudo, no sentido do que se compreende como espaço/ tempo da escola. Na linha de Jan Masschelein e Maarteen Simons (2013; 2014), defendemos a escola como um espaço público e um espaço livre, um espaço de estudo em que cada um é exposto a coisas. A escola como destinada a um tempo livre, "precisamente no sentido que o termo grego skholé parecia indicar - um espaço no qual o tempo (econômico, social, cultural, político, privado) é suspenso e no qual temos tempo a nosso dispor para um novo começo" (Masschelein e Simons, 2014, p. 197). No sentido de Hannah Arendt (2002), escola como um lugar para os recém-chegados, onde as coisas são trazidas à presença dos estudantes para que possam ser pensadas, para que tenham um significado positivo, que seja um lugar do comum.

A escola cria igualdade precisamente na medida em que constrói o tempo livre, isto é, na medida em que consegue, temporariamente, suspender ou adiar o passado e o futuro, criando assim, uma brecha no tempo linear. [...] Você é isso, então você tem que fazer aquilo, você pode fazer isso, então você entra aqui [...]. O espaço escolar não se refere a um espaço de passagem ou de transição (Masschelein e Simons, 2013, p. 36-37).

Docência, nessa perspectiva, se relaciona ao ofício do professor que torna possível a evocação da presença - considerando a relação entre a presença dos estudantes, da matéria de estudo e do professor - no espaço/ tempo da escola na ordem da suspensão. Esse é o conceito de docência no qual nos apoiamos.

Importa enfatizar a utilidade desses dois conceitos - governamentalidade e docência - para este empreendimento de pesquisa. Olhar para os modos como somos governados e conduzidos é fundamental para compreender nossa posição e função enquanto sujeitos que exercem uma docência nestes tempos. Igualmente, refinar o que compreendemos como docência é ponto de apoio para estabelecer uma problematização com o que vivemos.

Após essa definição dos conceitos, nos debruçamos sobre os materiais coletados junto aos professores, dos quais emergiram as discussões que passamos a apresentar na próxima seção.

\section{Discussão DE RESUltados}

Com o aporte teórico que sustenta nosso olhar, analisamos os questionários respondidos pelos docentes de Educação Física que participaram do estudo, tendo como foco o objetivo da pesquisa. Dentre os diferentes pontos levantados, trazemos duas situações que julgamos importantes de serem apresentadas neste momento, nomeadas como: Práticas de Educação Física e inclusão no ensino remoto e uma vivência de crise na docência em educação física inclusiva remota. Essas duas questões são discutidas nas subseções a seguir.

\section{Práticas de Educação Física e inclusão no ensino remoto}

O acompanhamento das práticas dos docentes de Educação Física no ano de 2020 mostra muitos deslocamentos em relação à docência na Educação Física escolar. Apontamos três situações pertinentes sobre esses deslocamentos, os quais ajudam a compreender a problematização proposta: os saberes trabalhados; o âmbito das aulas e as opções metodológicas.

No tocante aos saberes trabalhados, consideramos a distinção entre saberes conceituais, que seriam da ordem dos conhecimentos sobre condições sociais, culturais, críticas e históricas das práticas corporais; saberes corporais, abordando a ordem da vivência corporal das práticas corporais; e, saberes atitudinais, como da ordem das questões éticas. A análise mostra que os professores de Educação Física propuseram, inicialmente, levar saberes conceituais aos seus alunos, tal como a análise histórica das práticas corporais; regras de execução de diversos esportes; conhecimento sobre federações e organizações esportivas; dentre outros. Com o decorrer do ensino remoto, os professores passaram a conduzir saberes corporais, tais como o ensino de movimentos, a condução de exercícios, a realização de jogos, brincadeiras, danças, ginásticas, movimentos de lutas, entre outros. Não foi evidenciado o trabalho com saberes atitudinais. 
No que diz respeito ao âmbito das aulas, sobressai o uso das tecnologias de informação e de comunicação. A primeira ferramenta foi o aplicativo de rede social Whats $A p p$, utilizado para envio dos materiais, comunicação com as famílias e plantão de dúvidas. Além desse, destacam-se a página da rede social Facebook das escolas, os websites das escolas, o aplicativo Instagram, os provedores de e-mail e plataformas de reuniões, tais como Google Meet, Google Classroom, Zoom e Skype. Outro meio muito utilizado foi entrega e retirada de materiais pelos alunos: os alunos e/ou suas famílias vão até a escola e retiram os materiais planejados pelos professores, levam para casa e realizam as propostas. Muitas instituições e docentes lançaram mão dessas ferramentas de forma conjunta para tentar atingir a multiplicidade de alunos, considerando: condições de acesso, condições familiares e necessidades de estímulos diversos para a aprendizagem. Percebemos que as aulas ocorreram no âmbito da casa dos estudantes, ora mediadas por encontros síncronos entre professores e alunos, ora em aulas assíncronas.

Em relação às opções metodológicas, constatamos uma conexão entre o tipo de saber trabalhado, o âmbito das aulas e a metodologia. A depender dos recursos que os alunos, a escola e os professores dispunham, situavase a metodologia escolhida. Variaram muito entre o envio de materiais de leitura - digitais ou impressos - indicação de vídeos gravados pelos professores ou disponibilizados por outros e realização de encontros síncronos nas plataformas digitais. Há uma mudança nas opções metodológicas a partir do momento em que houve uma mudança de ênfase dos trabalhos com os saberes conceituais para os saberes corporais.

Com esse panorama, adentramos no tocante a realização das práticas com alunos ditos de inclusão. Ao considerar os tipos de saberes e as metodologias que estão sendo privilegiados neste momento, os professores trazem muitas questões que precisam ser pensadas. Vamos abordar três pontos: alterações e adaptações nas aulas; dificuldades de acesso a tecnologias; afastamento entre professores e alunos.

Em relação às alterações e adaptações nas aulas, docentes responderam que fazem atividades diferenciadas para os alunos de inclusão. A maior parte, ao enviar propostas para os alunos de inclusão, preferem as atividades que favoreçam o movimento do corpo, como alongamentos, passos de dança, atividades lúdicas, brincadeiras, jogos de socialização, solicitando que algum familiar possa auxiliá-los. Também relatam que fazem adaptações nos materiais escritos que são disponibilizados, como no tipo e no tamanho da fonte, nas descrições das atividades e na dimensão do material. Isso como uma forma de tornar o material mais compreensível. Contudo, evidenciam que não consideram estar trabalhando outros conteúdos, mas adaptando. Além disso, os professores relatam que, por vezes, atendem aos alunos de inclusão de forma individualizada, seja em atendimento on-line ou de forma presencial. Alguns relatam que a escola é aberta para receber certos alunos para um trabalho na sala de recursos e/ou outra. Todavia, nesse momento de atividade presencial na escola, apenas um professor está com esses alunos - geralmente o responsável pelas salas de Atendimento Educacional Especializado (AEE), salas de recurso ou orientação educacional. O professor de Educação Física não está presente. Nos excertos retirados do material de pesquisa podemos ver algumas dessas colocações. É importante marcar que os sujeitos da pesquisa foram identificados com letras e números para preservação de suas identidades.

O Colégio possui profissionais dedicados a esta questão. Estamos adaptando as atividades de acordo com as necessidades/ características dos alunos, e sempre existe um diálogo entre os professores, os profissionais e os pais destes alunos para saber se as atividades estão adequadas (Docente D2).

Para não deixar a aluna à margem do que está acontecendo no momento, a escola optou por recebê-la uma vez por semana na sala de AEE, com a professora de AEE, para realizar as atividades. Assim como ela, os outros alunos com deficiência e/ou dificuldades de aprendizagem estão recebendo o mesmo atendimento. É claro que isso quebra o isolamento, mas é uma opção de aumentar a exclusão desses alunos, no momento (Docente A2)

Eu não tenho nenhum aluno deficiente visual ou auditivo, mas percebo que há pouca inclusão neste caso, pois não há audiodescrição nos vídeos e nem linguagem de sinais. Alguns exercícios podem ser adaptados para cadeirantes e, no caso dos autistas, a explicação tem que ficar clara tanto ao aluno quanto aos pais (Docente E2).

A respeito das dificuldades de acesso a tecnologias, o relato é de que nem todos têm acesso, além de, por vezes, não contarem com apoio de familiares que sejam capazes de operar os recursos educacionais 
tecnológicos de que necessitam. Muitos alunos fazem uso, na escola regular, de softwares e hardwares específicos a suas necessidades. Todavia, nesta condição de ensino remoto, esses materiais ficaram na escola e os alunos não têm acesso. Nota-se um esforço dos professores para que os alunos acessem ao trabalho organizado para eles, mas há muitos entraves. As tecnologias de informação e de comunicação, embora sejam ferramentas potentes, ainda são recursos que excluem grande número de pessoas. Nas falas dos docentes:

Como professor da escola pública o principal problema tem sido a desigualdade de acesso (Docente EE2).

Pessoalmente não obtive retorno das tarefas enviadas, tanto pelos grupos de whats, classroom ou sala de recursos (Docente R2).

$\mathrm{Na}$ nossa escola temos alguns alunos especiais, porém, suas deficiências não os limitam a participar das aulas comuns de Educação Física. Não têm necessidade de nenhum material especifico ou método como Libras ou Braille. Porém, em outras escolas sabemos que existem, mas esse não são alcançados, porque o governo não ofereceu nenhum recurso para que tivessem acesso ao material (Docente B2).

Sobre o afastamento entre alunos e professores, notamos que as atuais formas de comunicação e a realização das tarefas escolares no âmbito das casas propiciam uma diminuição no vínculo e no envolvimento dos alunos. A ampla maioria dos docentes de Educação Física relata que não possui contato com os alunos, que as atividades são mediadas por outros setores, tais como salas de AEE, Serviço de Orientação Educacional e professoras das salas de recursos. A diminuição do contato entre professores e alunos dificulta $o$ favorecimento de processos inclusivos, pois a potência de estar com o outro é dificultada pela distância física. A aula presencial disponibiliza alternativas que o ensino remoto não oferece, principalmente por favorecer a interação e a vivência com o outro. Nas manifestações docentes:

A interação entre família e escola se dá através da professora tutora, que faz os relatos para os especializados. Diante desse contexto, não houve nada pontual de alunos de inclusão (Docente J2).

Tem sido complexo garantir a inclusão remotamente. Percebo que o trabalho tem sido realizado mais por orientadoras educacionais e centros de atendimento, não por falha docente, mas pela complexidade do processo (Docente H2).

Dentro da minha realidade as professoras das salas de recursos (AEE), tem entrado em contato direto com esse grupo com objetivo de auxiliá-los. Algumas atividades são adaptadas para alguns alunos em especial (mas nunca contempla o todo) (Docente F2).

Nossa escola tem um professor que trabalha diretamente com eles. Elaboramos as aulas e encaminhamos ao professor que nos ajuda nesta aprendizagem com eles (Docente N2).

Em relação a esses pontos, destacamos uma afirmação do professor Nuccio Ordine, na qual ele diz: "o contato com os alunos em sala de aula é o que pode dar verdadeiro sentido ao ensino e aí está incluída a própria vida do docente ${ }^{3}$. O âmbito das aulas em casa e o âmbito das aulas na escola traz significativas mudanças em relação à docência. $O$ professor argentino Mariano Narodowski colocou em circulação um projeto que foi chamado de "Onze teses urgentes para uma pedagogia do contraisolamento", um texto que busca trazer reflexões sobre este momento. Numa das passagens do texto ele afirma:

A casa é o oposto da escola. Uma escola é muito diferente de uma casa ou família. Uma escola é uma organização complexa, liderada por educadores especializados que ganham a vida com esse trabalho. Uma área que deve ser atendida em dias e horas socialmente prescritos e para aprender um conjunto de conhecimentos comuns a toda a população. Pelo contrário, casas não têm nada a ver com escolas, os relacionamentos entre seus membros formam um vínculo emocional ou primário de longo prazo, e ninguém se especializa profissionalmente ou recebe um salário por integrá-lo. Sair de casa para frequentar a escola significa estar indo do íntimo para o público; do diferenciado ao comum; do indivíduo para todos (Narodowski, 2020, p. 3).

É preciso considerar que a escola é o lugar em que as crianças aprendem a compartilhar coisas, a respeitar espaços e tempos coletivos, a viver com diferenças e diferentes. Veiga-Neto (2003) afirma que a educação familiar e a educação escolar são condições necessárias para a constituição desse tipo de individualidade que chamamos de sujeito moderno, possível graças à articulação complementar entre, por um lado, a aprendizagem de normas comportamentais e códigos morais na esfera restrita e particular da família e, por outro lado, a aprendizagem de novas normas e novos códigos na esfera ampla e plural da sociedade. 
Masschelein e Simons (2014), ao tratar do tempo escolar, afirmam que esse tempo deveria ser um tempo de estudo, um tempo do livre pensar como possibilidade de termos uma escola igualitária. Um espaço onde todos são capazes, um espaço de atenção, um espaço onde se pode iniciar algo novo e que pode mudar as condições das crianças "porque ela as tira do mundo (desigual) de produção (e do mundo desigual da família e da ordem social) e oferece a elas a magnificência de um tempo-espaço igualitário" (Masschelein e Simons, 2014, p. 109). Isso a difere de outros espaços, de outras instituições. Na perspectiva de Hannah Arendt é na escola que a criança vai do mundo privado - família - para o mundo público. Quando estamos no ensino remoto, com as aulas acontecendo no espaço doméstico, não temos essa condição e essa potência que podem ser advindas do espaço escolar. Ainda nas reflexões sobre as práticas no ensino remoto, trago as colocações de Lockmann (2020) ao afirmar a escola como espaço inapropriável. Para a autora:

[...] os processos que ali acontecem não podem ser reproduzidos em outros lugares, simplesmente porque eles se dão em um espaço aberto de criação e de invenção, o qual só pode ser produzido quando diferentes vozes, diferentes sujeitos, diferentes gerações, diferentes etnias, diferentes crenças e formas de vida se encontram (Lockmann, 2020, p.14).

Ao analisar as práticas referentes à Educação Física, em uma dimensão que se pretende inclusiva no ensino remoto, analisando os deslocamentos trazidos pelos professores, considera-se que estamos vivendo um tempo em que não temos presença docente, agravado por uma governamentalidade neoliberal fascista que não considera a escola como um tempo para o exercício do pensar. Essas questões acendem uma preocupação com o momento vivido, na medida em que estamos assistindo processos que podem acarretar situaçóes bastante excludentes. Não estar na escola, não conviver com o outro, estar distanciado, não ter acesso ao universo escolar, são cenários propícios - no contexto brasileiro atual - para que as exclusões sejam proliferadas.

\section{Uma vivência de crise na docência em educação física inclusiva remota}

Uma das mais referenciadas colocações do professor Jorge Larrosa é quando ele traz o conceito de experiência. Nas palavras do autor é sobre aquilo que "nos passa, o que nos acontece, o que nos toca" (Larrosa, 2002, p. 21). O autor também destaca que experiência não é informação e é algo raro nos dias de hoje em função de vivermos um momento de excesso de opinião, de uma falta de tempo e de um excesso de trabalho. Como sujeitos de uma formação permanente e acelerada, de uma atualização constante e que não pode perder tempo, que não pode ficar para trás e que precisa seguir velozmente, temos cada vez menos experiências.

A experiência, a possibilidade de que algo nos aconteça ou nos toque, requer um gesto de interrupção, um gesto que é quase impossível nos tempos que correm: requer parar para pensar, parar para olhar, parar para escutar, pensar mais devagar, olhar mais devagar, e escutar mais devagar; parar para sentir, sentir mais devagar, demorar-se nos detalhes, suspender a opinião, suspender o juízo, suspender a vontade, suspender o automatismo da ação, cultivar a atenção e a delicadeza, abrir os olhos e os ouvidos, falar sobre o que nos acontece, aprender a lentidão, escutar aos outros, cultivar a arte do encontro, calar muito, ter paciência e dar-se tempo e espaço (Larrosa, 2002, p. 27).

Em março de 2020, quando a docência brasileira foi conduzida ao modo de ensino remoto, não foi propiciada uma experiência. Reflexões pobríssimas, aceleração para a continuidade do ensino, soluções aligeiradas, nenhuma formação. Foi em cima dessa situação que se estabeleceu a docência no ensino remoto. As dificuldades se multiplicaram e continuam se multiplicando. De acordo com os docentes:

Falta de recursos ideais para esse tipo de aulas, o pouco retorno por parte dos estudantes, a falta de normativas para esse tipo de trabalho, as incertezas sobre o que será feito deste ano escolar e do próximo (Docente S2).

Minha maior dificuldade foi começar a fazer aulas síncronas, levou um temp. (Docente Y2).

Adaptação ao ensino remoto e o distanciamento no acompanhamento dos alunos (Docente GG2).

Em sua continuidade, os professores relatam que não estão abertos espaços de reflexão, de fala, de escuta, de atenção ao momento. $\mathrm{O}$ imperativo da aceleração e do não podemos parar - máximas de um modo de vida 
neoliberal - se sobrepuseram à necessidade da escuta, da troca, da paciência e do encontro. Os professores estão vivendo o ensino remoto e, alguns, sobrevivendo a ele, mas a oportunidade de transformar essa vivência em experiência está ficando à margem. Tal fato desarticula, por exemplo, uma possibilidade de se fazer deste momento uma experiência que pudesse ser capaz de promover outros sentidos ao que estávamos vivendo e produzindo antes do distanciamento social, um modo de reflexão sobre a docência que tínhamos e a que queremos. Em especial, destacamos que os professores de Educação Física escolar se sentem em crise em relação ao que desejavam e ao que estão conseguindo realizar. No exercício da Educação Física com proposta inclusiva há a necessidade de adaptações, mas a falta de estrutura e o afastamento inquietam a todos. Está sendo realizada e vivida outra situação. O desafio da inclusão neste modo remoto assume nuances que nos colocam em crise em relação ao que se realizava no modo presencial, fatos que geram desgastes e apreensões.

Para compreensão dessa sensação de crise trazemos o aporte de alguns autores. Podemos nos apoiar nos trabalhos de Bauman (2001) quando o autor identifica que, na raiz da permanente sensação de crise que vivemos está a acelerada liquefação do mundo contemporâneo. Nesse processo em que os sólidos se liquefazem, mudam as nossas relações com o espaço e o tempo, implicando na ideia de crise da Modernidade. Sobre essa sensação de crise, Veiga-Neto (2008) afirma que crise corresponde à distância entre aquilo que pensamos e planejamos para acontecer e aquilo que efetivamente acontece. "Nossa sensação de crise é a medida da diferença entre o esperado, sonhado, desejado e o obtido, atualizado, conseguido" (Veiga-Neto, 2008, p. 42). Todavia, na companhia de Hannah Arendt (2002), ela nos mostra que crise não deve ser entendida como algo, por si mesmo, negativo, mas como uma oportunidade de refletir, de modo a agir para tentarmos mudar o rumo dos acontecimentos, tendo, também, algo de positivo.

Nessa compreensão, o ensino remoto e os deslocamentos que nos geraram desconforto e sensação de crise não são, em si, o centro do problema. A questão está em como essas coisas têm sido pensadas, sentidas e transformadas em oportunidades de se avaliar sobre o tempo presente, pois, do modo como estão, acabam produzindo desconfortos, cansaços e esgotamentos docentes. Em recente artigo, as professoras Karla Saraiva, Clarice Traversini e Kamila Lockmann, argumentam que estamos vivendo uma exaustão docente:

A docência nos tempos de pandemia é uma docência exausta, ansiosa e preocupada. Que quer acertar, mas que avança no meio da incerteza e da adversidade - e que não tem a menor ideia do caminho. Como todos, os professores estão imersos em uma névoa e seguem através dela, buscando fazer o melhor, mas sem garantias. [...] A responsabilização dos professores tende a fortalecer a intensificação e a autointensificação do trabalho aumentando a exaustão docente. Há um difícil equilíbrio entre continuar as atividades letivas e administrar o momento atual que tem gerado estresse e ansiedade (Saraiva et.al., 2020, p. 17).

Em específico deste trabalho, o caso das práticas docentes que procuram modos de incluir na Educação Física escolar neste ensino remoto, é possível enxergar sinais de esgotamento - expressão presente na fala dos participantes da pesquisa. Tomamos esse conceito de esgotamento, em Língua Portuguesa, a partir de uma ideia de pensar em "esgotar" como fazer ficar ou ficar exausto; perder as forças; cansar; que, acrescido do sufixo "mento", pode representar resultado ou produto de uma ação. Ou seja, esgotamento como representativo do cansaço docente, resultado de diferentes ações sofridas pelos docentes. Aqui abordamos três dessas diferentes ações que fazem esgotar e contribuem para a crise vivida: corporal, financeira e emocional. Tais questões surgem a partir das colaborações dos professores na pesquisa, quando manifestam, por exemplo:

As condições de trabalho são precárias. Se antes trabalhávamos 20 horas semanais, agora são 60 horas. Pois, como atendemos pelo whatsapp, a orientação que recebemos é que o aluno não pode deixar de ser respondido, mesmo que seja em um horário não convencional, como as $23 \mathrm{~h}$ ou em um domingo as $21 \mathrm{~h}$. Por mais que tenhamos estabelecido um horário, por insistência nossa, com a direção, a orientação segue a mesma de que não podemos deixar de responder (Docente A2).

As condições tecnológicas para este tipo de trabalho são individuais e não houve nenhum tipo de subsídio (Docente B2).

Minha internet, meus equipamentos, meus livros. Se depender do Estado (talvez do município também), quanto mais eu investir neste processo, melhor para eles. Meu investimento é por interesse pessoal e acaba beneficiando as ações laborais. Falo de maior velocidade de internet, microfone, fone, telefone melhor (Docente C2). 
Temos que usar nossos recursos próprios, pois os recursos do governo como internet não funcionam. Temos que usar nos celulares e computadores. Muitos professores tiveram que adquirir novos equipamentos, devido a essa nova forma de trabalho (Docente N2).

Muito ruins. Com relação a parte humana, emocional, etc, Com relação a qualidade de tempo de trabalho, suporte da secretaria, acesso a tecnologias, tem sido muito ruim. Nossas casas não estavam preparadas para esse trabalho, não tem lugares ergonômicos e/ou confortáveis para trabalhar (Docente $\mathrm{H} 2$ ).

Um desgaste enorme no planejamento das aulas, construção de materiais de estudos, no processo prático da aula, na elaboração das avaliações e correções das atividades. O dia inicia pela manhã com aula síncronas e vai até a noite, $12 \mathrm{~h}$ de trabalho a frente do computador (Docente F2).

A começar pelo repertório de atividades que teve que ser construído praticamente do zero. $\mathrm{O}$ trabalho se tornou mais burocrático (preenchimento de planilhas, reunióes muito mais frequentes, correção de atividades que antes eram vistas e "corrigidas" no próprio desenvolvimento da aula) (Docente G2)

Uma saturação docente e discente (Docente U2).

A ação corporal que esgota os docentes se relacionaria a uma sobrecarga de trabalho, de estudos, de cursos, de planejar, de organizar, de replanejar, de reorganizar as aulas em um ritmo não antes praticado. A ação financeira diz respeito aos salários parcelados, reduzidos e descontados, que os governos do Brasil estão repassando aos professores, e ao aumento de despesas com internet, luz, computadores e outros aparatos para trabalhar no modo de ensino remoto. A ação emocional se relacionaria às pressões sociais que atacam a docência no Brasil, às incertezas sanitárias e aos ataques governamentais que desqualificam e agridem professores, pautados no momento político que vivemos, além do afastamento dos professores das atividades presenciais com seus alunos. Ações que, dirigidas aos docentes, cansam, levam à exaustão, provocam um esgotamento.

Junta-se a isso os deslocamentos que a Educação Física escolar sofreu no ensino remoto, se diferenciando, sobremaneira, de práticas precedentes. Um esgotamento potencializado por uma crise daquilo que vivíamos, lutávamos, acreditávamos e que não está se efetivando neste momento. As potências inclusivas que vivíamos na Educação Física escolar não estão presentes. Os professores vivem uma reinvenção cotidiana para dar conta das atuais demandas sem ter um tempo para refletir. Estamos vivendo outra Educação Física, outra inclusão e outro currículo e isso, acrescido dos modos atuais de governo, gera instabilidade, sensação de crise, esgotamento.

O que temos vivido se afasta, tanto do que a Modernidade projetou para a escola - um modelo de disciplinamento corporal pautado no convívio com o outro - quanto daquilo que pensadores como Masschelein e Simons (2013; 2014) defendem sobre como deveria ser a escola, o espaço do livre pensar. O que temos no contexto do ensino remoto é um foco na disciplina no campo saber, sem o convívio com o outro e ainda mais afastado do livre pensar. O ensino tem outro foco e os espaços das aulas mudaram. Importa destacar que o distanciamento do espaço físico da escola traz muitos efeitos para a docência, tendo em vista que esse é o lugar reconhecido para tanto. Como nos lembra Larrosa:

A escola é para o professor o que a padaria é para o padeiro, a cozinha é para o cozinheiro ou o sapato é para o sapateiro: sua oficina, seu laboratório (se entendemos por laboratório o lugar do seu labor), seu ateliê (se entendermos por ateliê o lugar onde ele atua), o lugar onde ele exerce seu ofício, onde mostra suas habilidades e onde estão tanto suas matérias-primas quanto suas ferramentas ou seus artefatos (Larrosa, 2018b, p. 27).

Não se substitui a escola, tanto para o aluno quanto para o professor, o que acontece naquele espaço plural, de convivência, de encontro, de aprendizagens, não pode ser reproduzido em outros contextos. É único. $\mathrm{Na}$ Educação Física escolar, o desenrolar das aulas nas quadras, nos pátios, nos campos, embaixo das árvores, nas salas, nos laboratórios, nas bibliotecas e em outros tantos espaços possíveis de desenvolver esses encontros, não pode ser substituído pela intermediação das telas. 


\section{CONCLUSÕES: CONSIDERAÇÕES SOBRE O TEMA}

A pesquisa desenvolvida com o objetivo de problematizar a docência de professores de Educação Física escolar no contexto das aulas remotas no Brasil, focando no trabalho com os alunos considerados de inclusão traz distintos apontamentos para o contexto atual. Para começar, retomamos as aproximações entre inclusão e as políticas neoliberais, as quais, em que pesem distintas análises, colaboraram para incluir diferentes sujeitos na atual realidade social. Todavia, com deslocamentos de uma governamentalidade neoliberal para uma aproximação a um viés fascista, notamos um esvaziamento dessas políticas e uma ênfase em práticas de exclusão por parte do Governo brasileiro.

Dentro dessa moldura está a tela em que se situam as atuais práticas docentes no ensino remoto. $\mathrm{Ou}$ seja, a docência no ensino remoto, dentre as inúmeras situações difíceis que vivencia, também enfrenta um momento político e social que, ao que parece, trabalha numa busca pela exclusão de diferentes sujeitos.

Ao abordarmos a relação entre a Educação Física escolar e os processos de inclusão os professores relatam que, embora haja um trabalho docente que busca a inclusão, há dificuldades em relação ao acesso desses alunos às aulas, bem como há um afastamento deles em relação aos seus professores e aos demais colegas. Processos totalmente distintos do que tínhamos quando das aulas presencias, em que a maioria das práticas desenvolvidas nas aulas de Educação Física procurava favorecer a vivência com o outro e a potência da diferença. Ademais, temos a situação das questões de ensino e de aprendizagem da Educação Física que estão se desenvolvendo de modo muito diverso em relação ao que tínhamos no ensino presencial. Tais situações nos possibilitam refletir sobre a importância do contato e do espaço escolar para a docência contemporânea, em especial para uma Educação Física que busca potencializar a inclusão. O ensino remoto se afasta desses princípios e, além disso, no contexto brasileiro - onde as desigualdades sociais, as diferenças econômicas e as vontades políticas são insidiosas - pode favorecer práticas de exclusão.

Consideramos que a falta do contato presencial com os alunos, a sobrecarga de trabalho junto aos ataques à docência, as distintas formas de ensino da Educação Física no ensino remoto, as desigualdades do contexto social e econômico brasileiros e os processos de exclusões de alguns alunos com deficiência de aulas de Educação Física podem contribuir para um esgotamento dos professores que estão envolvidos com esses processos. Contudo, espera-se que essa situação vivida no ensino remoto, em especial em relação às aulas de Educação Física e às aulas de Educação Física inclusivas, não sirvam como laboratórios para o exercício de uma docência alinhada a uma perspectiva educacional que exclua o outro. Queremos estar com o outro, sentir a diferença, ser presença na arte do ser professor.

Ao finalizar, importa sublinhar que precisamos falar e refletir sobre as formas de viver a diferença nas práticas docentes que povoam este tempo, dentro de um olhar para o outro que compreenda seus sentidos, seus modos de estar no mundo e de aprender. É nisso que precisamos investir.

\section{REFERÊNCIAS:}

Arendt, H. (2002). A crise na Educação. In: Arendt, Hannah. Entre o passado e o futuro. São Paulo: Perspectiva. Bauman, Z. (2001). Modernidade Líquida. Rio de Janeiro: Jorge Zahar.

Foucault, M. (1997). Resumo dos Cursos do Collège de France (1970-1982). Rio de Janeiro: Jorge Zahar.

Foucault, M. (2008). Segurança, Território, População. São Paulo: Martins Fontes.

Foucault, M. (2008b). Nascimento da Biopolítica. São Paulo: Martins Fontes.

Foucault, M. (2011). Do Governo dos Vivos: curso no Collège de France 1979- 1980: Excertos. SP/RJ: Achiamé.

Gallo, S. (2013). Infância e Resistência - resistir a quê? Leitura: Teoria \& Prática, 31 (61), 199-211.

Lazzarato, M. (2019). Fascismo ou Revolução? O neoliberalismo em chave estratégica. São Paulo: n-1 Edições.

Larrosa, J. (2002). Notas sobre a experiência e o saber de experiência. Revista Brasileira de Educação.19, 20-28. 
Larrosa, J. (2018). Esperando não se sabe o quê: sobre o oficio de professor. Belo Horizonte: Autêntica.

Larrosa, J.; Rechia, K. (2018b). P de Professor. São Carlos: Pedro \& João Editores.

Lockmann, K. (2020). Governamentalidade neoliberal fascista e o direito à educação. Práxis Educativa, 15, e2015408, 1-18. Disponível em: https://doi.org/10.5212/PraxEduc.v.15.15408.061.

Lopes, M. C. (2009). Políticas de Inclusão e Governamentalidade. Educação e Realidade, 34 (2).

Lopes, M. C. ; Fabris, E. H. (2013). Inclusão \& Educação. Belo Horizonte: Autêntica.

Masschelein, J.; Simons, M. (2014). A pedagogia, a democracia, a escola. Belo Horizonte: Autêntica.

Masschelein, J;Simons, M. (2013). Em defesa da escola: uma questão pública. Belo Horizonte: Autêntica.

NarodowskI, M. (2020). Onze teses urgentes para uma pedagogia do contra-isolamento. [Título original: 11 tesis urgentes para una pedagogia del contra aislamiento. Enviado especialmente ao Pensar a Educação, Pensar o Brasil - 1822/2022 por Mariano Narodowski. Tradução para o português com o apoio de Tania Gi]. Disponível em: https://pensaraeducacao.com.br/blogpensaraeducacao/onze-teses-urgentes-para-uma-pedagogia-do-contr a-isolamento. Acesso em 05 de outubro de 2020.

Saraiva, K.; Traversini, C.; Lockmann, K.(2020). A educação em tempos de COVID-19: ensino remoto e exaustão docente. Práxis Educativa, 15, e2016289, 1-24. Disponível em: https://doi.org/10.5212/PraxEduc.v.15.16289 .094 .

Silva, T. T. da (1994). "Adeus às Metanarrativas Educacionais". In: silva, Tomaz Tadeu da. (org.). O Sujeito da Educação: estudos foucaultianos. Petrópolis: Vozes, pp. 247-258.

Veiga-Neto, A. (2003). Pensar a escola como uma instituição que pelo menos garanta a manutenção das conquistas fundamentais da Modernidade. In: costa, Marisa Vorraber (org.). A escola tem futuro? RJ: DP\&A.

Veiga-Neto, A. (2008). Crise da modernidade e inovações curriculares: da disciplina para o controle. In: Peres, Eliane et. al. (Orgs.). Trajetórias eprocessos de ensinar e aprender: sujeitos, curriculos e culturas. Porto Alegre: EDIPUCRS, pp. 35-58.

\section{Notas}

1 Informação completa após aprovação. Omitido para fins de preservação de identidade.

2 Informação completa após aprovação. Omitido para fins de preservação de identidade.

3 Disponível em: https://www.youtube.com/watch?v=tZkQRZ-18Kg. Acesso em 20 de junho de 2020. 